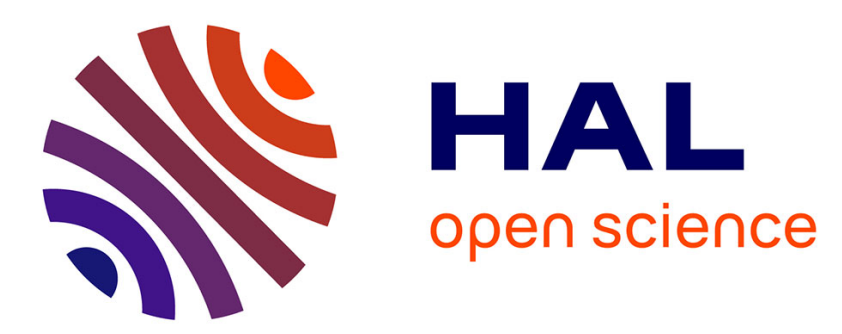

\title{
Coulomb mechanics and relief constraints explain landslide size distribution
}

Louise Jeandet, Philippe Steer, Dimitri Lague, Philippe Davy

\section{To cite this version:}

Louise Jeandet, Philippe Steer, Dimitri Lague, Philippe Davy. Coulomb mechanics and relief constraints explain landslide size distribution. Geophysical Research Letters, 2019, 46 (8), pp.4258-4266. 10.1029/2019GL082351 . insu-02097530

\section{HAL Id: insu-02097530 https://hal-insu.archives-ouvertes.fr/insu-02097530}

Submitted on 25 Jun 2019

HAL is a multi-disciplinary open access archive for the deposit and dissemination of scientific research documents, whether they are published or not. The documents may come from teaching and research institutions in France or abroad, or from public or private research centers.
L'archive ouverte pluridisciplinaire HAL, est destinée au dépôt et à la diffusion de documents scientifiques de niveau recherche, publiés ou non, émanant des établissements d'enseignement et de recherche français ou étrangers, des laboratoires publics ou privés. 


\section{Geophysical Research Letters}

\author{
RESEARCH LETTER \\ 10.1029/2019GL082351 \\ Key Points: \\ - We developed a mechanical model \\ to infer the distribution of landslide \\ depths in a given landscape, \\ accounting for hillslope geometry \\ - We demonstrate the role of hillslope \\ length, slope, and concavity in setting \\ the distribution of landslide sizes \\ - Hillslope geometry, not only slope, \\ may have a large impact on the \\ total landslide volume of sediments \\ triggered by earthquakes or storms
}

Supporting Information:

- Supporting Information S1

Correspondence to:

L. Jeandet,

louise.jeandet@univ-rennes1.fr

Citation:

Jeandet, L., Steer, P., Lague, D., \& Davy, P. (2019). Coulomb mechanics and relief constraints explain landslide size distribution. Geophysical Research Letters, 46, 4258-4266. https://doi.org/ $10.1029 / 2019$ GL082351

Received 3 FEB 2019

Accepted 2 APR 2019

Accepted article online 8 APR 2019

Published online 17 APR 2019

(C)2019. American Geophysical Union. All Rights Reserved.

\section{Coulomb Mechanics and Relief Constraints Explain Landslide Size Distribution}

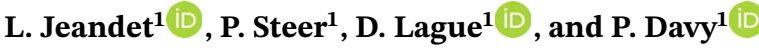 \\ ${ }^{1}$ Université de Rennes, CNRS, Géosciences Rennes-UMR 6118, F-35000 Rennes, France
}

\begin{abstract}
Despite the idea that topography could control landslide size scaling law, the contribution of landscape geometry to landslide size distribution remains elusive. We define a simple mechanical model accounting for the complexity and variability of natural hillslopes to infer the landslide depth probability density function (PDF) in a given landscape and upscale it to landslide area PDF. This model is based on both a Mohr-Coulomb stability analysis, accounting for cohesion and friction, and a criterion of intersection between rupture planes and the topographic surface. It can reproduce the distribution of observed landslide areas triggered by several past events. We found the ranges of effective cohesion (10-35 $\mathrm{kPa})$ and friction $\left(20-45^{\circ}\right)$ consistent with previous estimates of large-scale rock strength. Using synthetic topographies, we found that the finite geometry of hillslopes (length, steepness, and concavity) exerts a first-order control on the PDF of landslide areas, especially for large landslides.
\end{abstract}

\section{Introduction}

In mountainous areas, the numerous landslides triggered by earthquakes or storms represent a major hazard and contribute significantly to surface erosion (Keefer, 1994; Malamud et al., 2004b). Assessment of the total volume of such landslides is required to quantify the topographic changes in response to large earthquakes or rainfall events (Hovius et al., 2011; Li et al., 2014; Marc et al., 2016; Parker et al., 2011). The frequency distribution of landslide area is a basic requirement for estimating large-scale landslide erosion using nonlinear empirical relationships between landslide area and volume (Larsen et al., 2010). This distribution, generally characterized by a negative power law for landslide areas larger than a given threshold, and a rollover for smaller landslides (Guzzetti et al., 2002; Korup, 2005; Malamud \& Turcotte, 1999; Stark \& Hovius, 2001), is considered a universal property of landscapes regardless of the geological setting or triggering mechanism (Malamud et al., 2004a). However, the origin of this power law behavior and the controls on the inferred power law exponent, ranging from -1.42 to -3.36 (Van Den Eeckhaut et al., 2007), remain unclear. Several studies have suggested that mechanical heterogeneities, such as the size distribution of moisture patches (Pelletier et al., 1997) or fractures (Katz \& Aharonov, 2006), control the frequency distribution of landslide size and its power law exponent. However, previous numerical studies (Stark \& Guzzetti, 2009) modeled a power law distribution of landslide sizes using homogeneous materials. Stark and Guzzetti (2009) showed that landslide size power law scaling is an emerging feature of a simple mechanical model where landslide rupture and propagation behave as stochastic survival processes. However, to reproduce the observed probability density function (PDF) of landslide areas, they needed to incorporate variability and randomness in both the initial rupture depth and area.

Despite many observations showing that large landslides $\left(V>10^{8} \mathrm{~m}^{3}\right)$ are more frequent on high and steep landscapes (e.g., Blöthe et al., 2015; Korup et al., 2007), the actual role of topography on landslide size PDF has been poorly investigated. Cellular automaton models applying a stability criterion to natural topographies (Alvioli et al., 2014; Liucci et al., 2017) managed to reproduce the frequency-size statistics of landslides. This implies topography has an important role in controlling landslide size distribution, supporting the hypothesis of Frattini and Crosta (2013) that the fractal distribution of areas of high slope may control the power law scaling of landslide area. However, as sliding only occurs at the soil-rock transition in cellular automaton models, they are only appropriate to simulate landsliding occurring at shallow depth and not for bedrock landslides that involve deep-seated rupture planes at any depths. Thus, it remains unclear how rock mechanics and landscape geometry influence the overall distribution of bedrock landslide sizes. In this paper, we focus on the distribution of the whole range of potential rupture depths for a given landscape. Our goals are to (1) define a simplistic yet robust 1-D mechanical model of landslide rupture accounting for 
a)

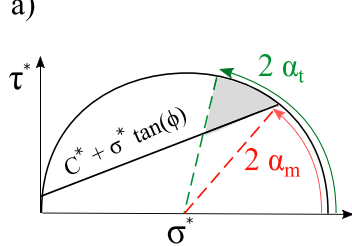

b)

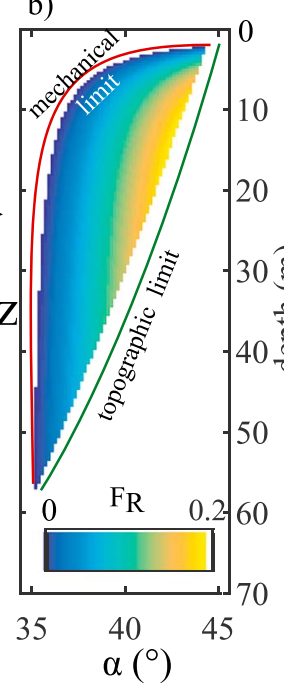

c)

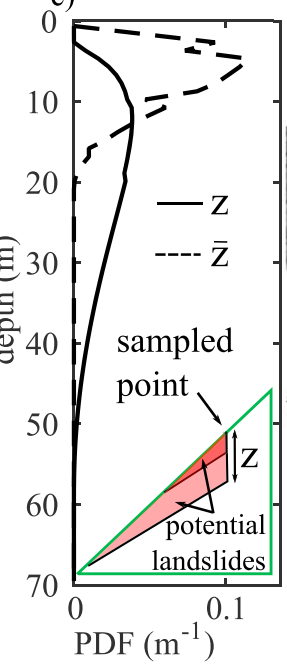

d)

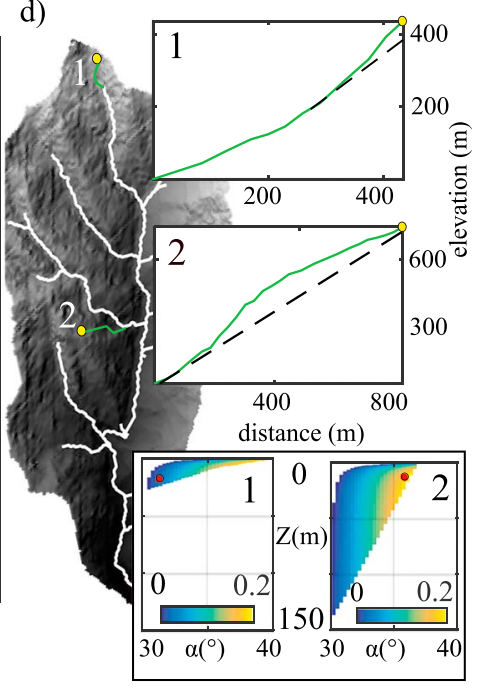

Figure 1. Modeling approach used in this study. (a) Mohr circle (top) and schematic hillslope (bottom) showing the range of potential rupture planes (in gray) at a certain depth $z \cdot \tau^{\star}$ and $\sigma^{\star}$ are shear and normal stress. $\alpha_{m}$ is the minimum rupture angle with $F_{R}>0$, and $\alpha_{t}$ is the maximum rupture angle allowed by the topography. (b) $F_{R}$ as a function of rupture angle and depth for an idealized $50^{\circ}$ slope of $500-\mathrm{m}$ height $\left(C=5 \mathrm{kPa}\right.$ and $\phi=30^{\circ}$ ). (c) PDF of maximum vertical depth $(z)$, and mean depth orthogonal to the surface $(\bar{z})$. The inset shows the geometry of two landslides with the same rupture angle but different depths. (d) Hillslope profiles (green lines) extracted from two sampled points (yellow dots), with one possible rupture plane (red dots in the bottom insets showing the corresponding unstable zones). $\mathrm{PDF}=$ probability density function.

the influence of hillslope geometry and reproducing the size distribution of landslides and (2) use this new model to determine the contributions of mechanical parameters and landscape geometry in controlling the landslide size distribution in various mountainous areas.

\section{Methods}

We developed a simple 1-D probabilistic method to infer distributions of landslide depths in a given digital elevation model (DEM), and then upscale the results to area PDF via a scaling argument. We focus on bedrock landslides, which represent the largest volume of failed material after large earthquakes or storms (Burbank, 2002; Dussauge et al., 2003). We choose a simple approach involving a small number of parameters, and that does not need to involve a priori triggering event. Therefore, we use a static formalism and assume that rocks and soil behave as Mohr-Coulomb materials, and that failure occurs only if the shear stress acting on potential rupture surfaces exceeds the resisting shear strength of the material, set by the frictional angle $\Phi$ and cohesion $C$. The novelty in our approach results from combining a local and very simple stability mechanical criterion with topographic constraints. The underlying idea is that every plane is a potential landslide rupture plane regardless of the plane's depth and the corresponding dip angle, given the following conditions: (1) the plane is locally unstable under Mohr-Coulomb laws (mechanical criterion) and (2) the plane intersects the topographic surface in the downslope direction of the instability (topographic criterion; Figure 1). Previously developed models that integrated landsliding in landscape evolution models (Densmore et al., 1998) used a mechanical stability criterion based on finite slope mechanics and propagated the most unstable failure plane upslope, starting from the hillslope toe (Figure S2 in the supporting information). Because many landslides do not initiate at the hillslope toe, our model integrates all potential failure depths and angles in a landscape, which has not been attempted yet. Landslides triggered by earthquakes follow a complex spatial distribution that depend on many parameters such as peak ground acceleration (Meunier et al., 2007), slope pattern (Roback et al., 2017), or the distance from the fault (Massey et al., 2018). The objective of our paper is not to develop a predictive approach that would infer landslide spatial distribution, but to develop a simple and robust mechanical framework capable of deciphering the role of topography and mechanics on landslide size distribution. The introduction of triggering parameters is beyond the scope of this study. We now describe the different methodological steps of our landsliding model. 
Mechanical criterion. We propose that below a certain point $(x, y)$ of the topography, a potential rupture plane $\mathrm{P}_{l}(x, y, z, \alpha)$, characterized by a local maximum vertical depth $z$ (in meters) and a dipping angle $\alpha$, is mechanically unstable if locally the driving stress $\mathrm{S}_{d}(z, \alpha)$ exceeds the failure resistance stress $S_{r}(z, \alpha$; Figure 1a). This is usually expressed as a factor of safety (e.g., Duncan \& Christopher, 2004). Here, to assess the probability of failure, we define a mechanical rupture factor:

$$
F_{R}(\alpha, z)=\frac{S_{d}(\alpha, z)}{S_{r}(\alpha, z)}-1
$$

We only consider the largest component of the stress tensor $\sigma_{1}$, which we assume to be vertical and to depend simply on rock mass (neglecting the soil layer) $\sigma_{1}(z)=\rho_{r} g z$, with $\rho_{r}$ the rock density, set to $2,700 \mathrm{~kg} / \mathrm{m}^{3}$ and $g$ the gravitational acceleration $\left(g=9.81 \mathrm{~s}^{-2}\right) . \tau(\alpha, z)$ and $\sigma_{n}(\alpha, z)$ are the parallel and normal components of $\sigma_{1}(z)$ with respect to the failure plane, respectively. The resisting strength to failure is proportional to $\sigma_{n}$ $: S_{r}(\alpha, z)=C+\tan (\Phi) \sigma_{n}(\alpha, z)$. Assuming that $S_{d}(\alpha, z)=\tau(\alpha, z)$, we can write the rupture factor:

$$
F_{R}(\alpha, z)=\frac{\sin (\alpha)}{\frac{C}{\rho_{r} g z \cos (\alpha)}+\tan (\Phi) \cos (\alpha)}-1
$$

Equation (2) emphasizes the contribution of cohesion to shallow plane stability. At greater depths ( $0-3 \mathrm{~m}$; Figure S7), the resistance to failure is almost frictional and $F_{R}$ approaches the rupture factor of a cohesionless material:

$$
F_{R}(\alpha, z)=F_{R}(\alpha)=\frac{\tan (\alpha)}{\tan (\Phi)}-1
$$

Previous stability analyses included a depth-dependent cohesion profile (Frattini \& Crosta, 2013; Milledge et al., 2014) or fluid pressure (Alvioli et al., 2014; Stark \& Guzzetti, 2009). Those alternate formulations imply a preexisting soil/rock boundary or an unsaturated/saturated transition. We choose not to introduce depth-dependent complexity in the model to isolate the contribution of hillslope geometry, friction, and cohesion in the distribution of potential rupture depths.

Topographic criterion. For each sampled point $(x, y)$, we extract the downslope topographic profile to the river using a steepest-descent algorithm (Schwanghart \& Scherler, 2014). To take into account hillslope geometry, we define a topographic rupture factor $\mathrm{T}_{R}(x, y, z, \alpha)$ :

- $T_{R}(x, y, z, \alpha)=1$ if the plane $(\alpha, z)$ intersects the topography

- $T_{R}(x, y, z, \alpha)=0$ otherwise

We account for any unstable plane if its local tangent daylights above the valley bottom. We assume planar failure, because it provides the simplest shape and does not require additional parameters. We assume a vertical rupture immediately above the rupture point, leading to a triangular landslide of maximum depth $z$, characterized by an increasing concavity with rupture depth (Figure 1c). For each rupture plane $(\alpha, z)$, we compute the mean of rupture depths orthogonal to the rupture plane, $\bar{z}$.

As the probability of intersecting with the topography decreases with vertical depth (Figures 1a and S3), this criterion reduces the probability of deep rupture planes. Without this constraint, deep planes having the same rupture factor (equation (3)) would have the same rupture probability.

Rupture probability. We define the chance of rupture $\mathrm{P}_{R}(x, y, z, \alpha)$ by

$$
P_{R}(x, y, z, \alpha)=\max \left(F_{R}, 0\right)^{p} \times T_{R}(x, y, z, \alpha)
$$

We set $p=1$ (see supporting information S1). The grouping of possible landsliding planes at one location $(x, y)$ can be represented in a Mohr circle using a range of potential rupture angles (Figure 1a) for a given depth $z$. This defines an "angle-depth" unstable domain (Figure 1b) where the right and left boundaries are set by the topographic slope angle and the mechanical parameters, respectively.

Landscape-scale PDF of unstable depths. Local chances of rupture are computed for $n_{\text {sample }}=10,000$ points randomly sampled in the same DEM. We integrate the chances of rupture to obtain the total chances of ruptures for the DEM:

$$
P_{R, \mathrm{DEM}}(\alpha, z)=\int_{x} \int_{y} P_{R}(x, y, z, \alpha) \mathrm{d} x \mathrm{~d} y
$$



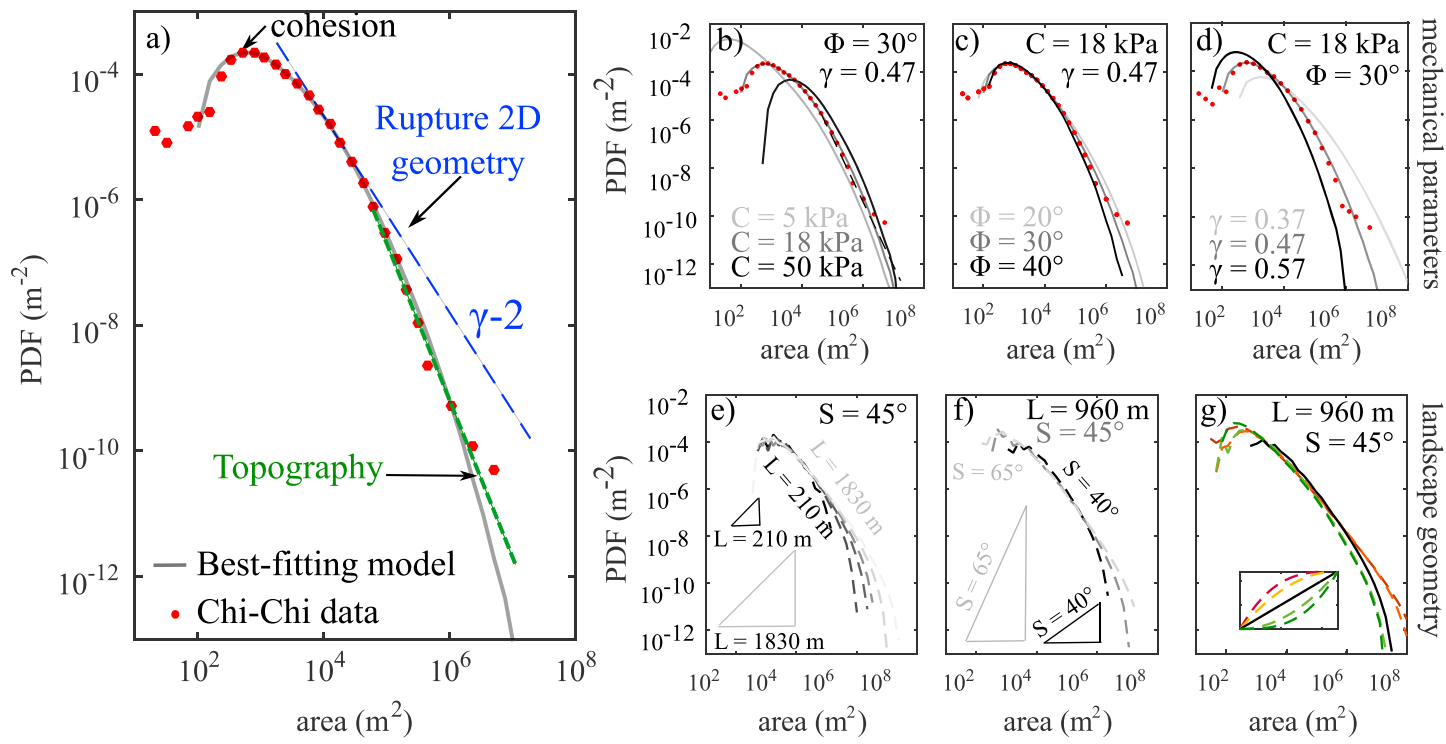

Figure 2. (a) Observed (red dots) and modeled (gray line) PDF of landslide areas from the Taiwan digital elevation model with $C=18 \mathrm{kPa}, \Phi=30^{\circ}$, and $\gamma=$ 0.47. Blue line shows the theoretical slope of the PDF arising from 2-D landslide geometry, and green line shows the slope of the part of the PDF mostly controlled by landscape shape. (b-d) The influence of changing the cohesion, the friction angle, or the landslide area-depth scaling exponent $\gamma$. (e-g) The PDF of landslide area computed on synthetic triangular prisms with a slope of $45^{\circ}$ and various height (e), unique length of $960 \mathrm{~m}$, and various slopes (f) or the same height and length but with different concavities (g). $C=10 \mathrm{kPa}, \Phi=35^{\circ}$, and $\gamma=0.42$. PDF $=$ probability density function.

We finally compute the PDF of unstable depths by integrating over all possible angles and normalizing:

$$
\operatorname{PDF}(z)=\frac{\int_{0}^{\pi / 2} P_{R, \mathrm{DEM}}(\alpha, z) \mathrm{d} \alpha}{\int_{z_{\min }}^{z_{\max }} \int_{0}^{\pi / 2} P_{R, \mathrm{DEM}}(\alpha, z) \mathrm{d} \alpha \mathrm{d} z}
$$

Correction from oversampling. Equation (6) does not provide the number of landslides but the number of points potentially included in landslides. Since large landslides include several points in the same slope failure, we systematically overestimate the probability of large landslides compared to smaller landslides. We demonstrate in the supporting information (S1) that using the empirical relationship between landslide depth and area $z=\alpha A^{\gamma}$ (Larsen et al., 2010), with $\gamma$ an exponent varying between 0.3 and 0.6 , we can deduce the PDF of landslide depth from the PDF of triggered points by dividing the latter PDF by $z^{1 / \gamma}$. We also demonstrate that applied to a theoretical, straight hillslope, this normalization introduces a power law scaling $P D F(z) \propto z^{-\gamma}$ in the landslide depth PDF.

Landslide area PDF. Since estimated landslide inventories are compiled as a distribution of landslide area and not depth, we use the scaling between depth and area to convert the modeled PDF of landslide mean depths to a PDF of landslide area, resulting in a scaling $\operatorname{PDF}(A) \sim A^{\gamma-2}$ (supporting information S2). Interestingly, this predicts that the PDF of areas for cohesionless landslides should follow a power law, which is consistent with the most heavy tailed distributions of landslides observed in nature. However, it predicts an exponent between -1.7 and -1.4 , much smaller than typically observed PDFs with exponents down to -3 (Van Den Eeckhaut et al., 2007).

Model parameters. Among the model parameters $\left(\rho_{r}, g, C, \Phi, p\right.$, and $\left.\gamma\right)$, the last four are not well constrained. Cohesion is a scale-dependent parameter, spanning several orders of magnitude in natural systems (Sutcliffe et al., 2004; Sidle \& Ochiai, 2006). Lab experiments define rock frictional angle $\Phi$ from $20^{\circ}$ to $45^{\circ}$ (Hoek \& Brown, 1997). The depth-area coefficient $\gamma$ varies regionally from 0.3 to 0.6 for bedrock landslides (Larsen et al., 2010). We vary $\Phi$ between $10^{\circ}$ and $60^{\circ}, C$ between 5 and $100 \mathrm{kPa}$, and $\gamma$ between 0.2 and 0.7 (Figure 3). We ran the model on six DEMs (Figure S6) corresponding to catalogues of landslides triggered by the $1999 \mathrm{M}_{w}$ 7.6 Chi-Chi earthquake (Liao \& Lee, 2000), the $2004 \mathrm{M}_{w} 6.6$ Niigata earthquake (GSI, 2005), the $2008 \mathrm{M}_{w} 7.9$ Wenchuan earthquake (Xu et al., 2014), the $2015 \mathrm{M}_{w} 7.8$ Gorkha earthquake (Roback et al., 2017), the $1994 \mathrm{M}_{w} 6.7$ Northridge earthquake (Harp \& Jibson, 1995), and the 2009 Morakot Typhoon (Chang et al., 2014; Marc et al., 2018). To optimize the unknown parameters values $(C, \Phi$, and $\gamma$ ), we compute the mean absolute distance between the logarithms of modeled and observed PDF of landslide areas, $d_{\mathrm{FIT}}$. 

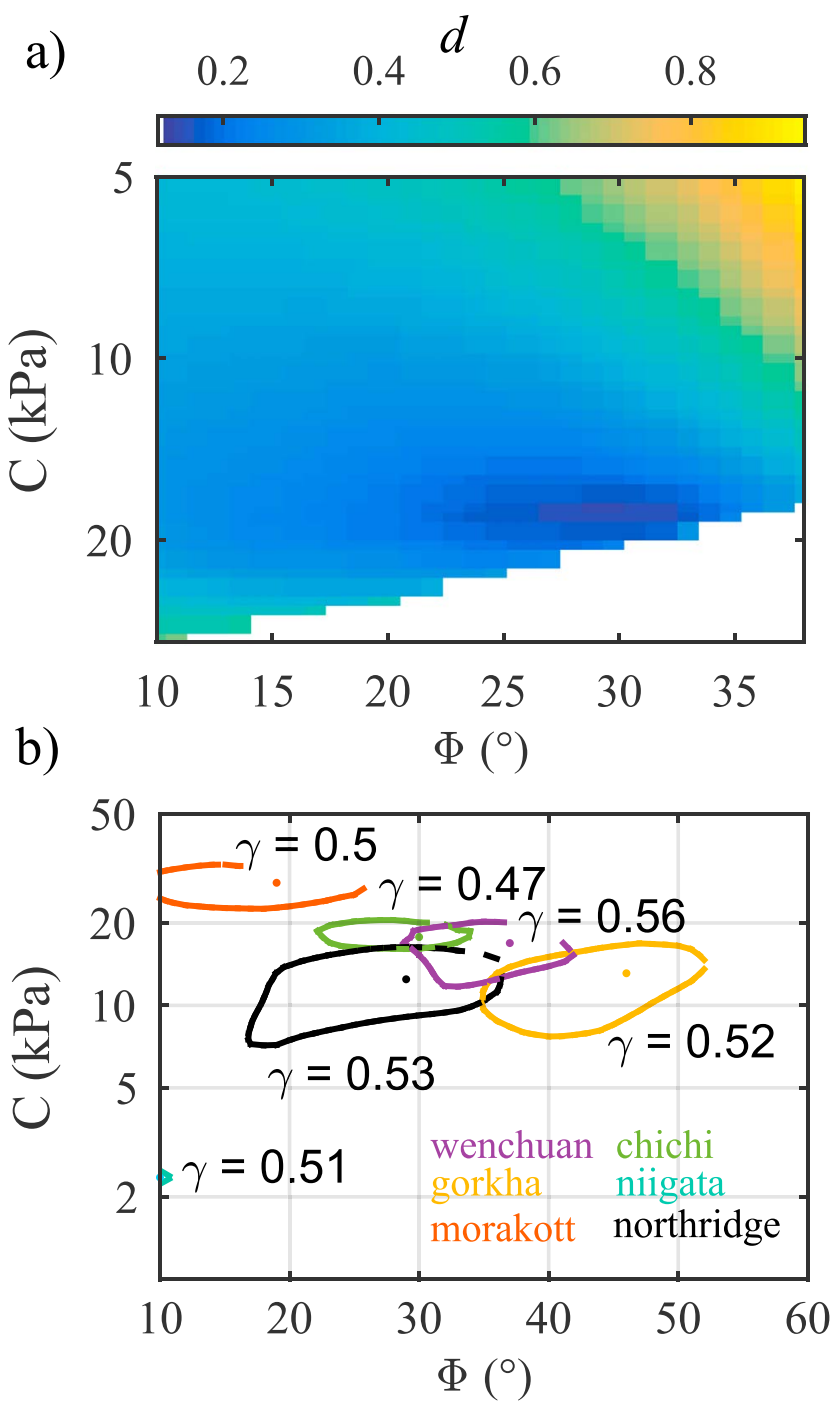

Figure 3. (a) Distribution of $d_{\mathrm{FIT}}$ for Chi-Chi earthquake-triggered landslides, as a function of friction and cohesion, with $\gamma=0.47$. The best fit values are $\gamma=0.47, \Phi=30^{\circ}$, and $C=18 \mathrm{kPa}$. (b) Best fit range of cohesion and friction $\left(d_{\mathrm{FIT}}\right.$ $=0.2$ contour), for the best fit $\gamma$ value. The dot shows the best fit parameters.

\section{Results}

Figure 2a shows the PDF of landslide area computed by applying the model to the DEM of Taiwan (Shuttle Radar Topography Mission at $30 \mathrm{~m}$ resolution) in the area affected by the $\mathrm{M}_{w} 7.6$ Chi-Chi earthquake. The best fitting parameters are $C=18 \mathrm{kPa}, \Phi=30^{\circ}$, and $\gamma=0.47$ (see Figure 3a). To first order, the modeled PDFs reproduce the observed PDF with a rollover behavior for small landslides, a power law decay for medium and large landslides, and a cutoff at large area. The correction from oversampling introduces a power law scaling $\operatorname{PDF}(A) \propto A^{\gamma-2}$ (supporting information S2) that holds for medium landslides $\left(5.10^{3}-10^{5} \mathrm{~m}^{2}\right)$. Over several orders of magnitude $\left(10^{5}-10^{7} \mathrm{~m}^{2}\right.$ ), the data are better modeled by a larger (by $\left.~ 60 \%\right)$ power law exponent. Figures $2 \mathrm{~b}-2 \mathrm{~d}$ show the impact of mechanical parameters on the modeled PDF. Cohesion is necessary for the emergence of a rollover (Figure S3), as it increases shallow plane stability (equation (2)). Increasing cohesion shifts the location of the rollover toward larger area or depth values (Figure 2b). For $\Phi=$ $30^{\circ}$, a cohesion between 15 and $20 \mathrm{kPa}$ is required to match the observed rollover positions ranging from 100 to $1,000 \mathrm{~m}^{2}$ (Malamud et al., 2004a). Increasing $\Phi$ decreases the probability of large landslides $\left(>10^{5} \mathrm{~m}^{2}\right.$ in Figure 2c). Decreasing $\gamma$ produces larger landslides and shifts the rollover toward larger values (Figure 2d).

In our model, natural topography is an input parameter including some variability. To explore the effects of the hillslope slope $S$, the hillslope length $L$ (i.e., horizontal distance to the river), and the concavity, we 
run the model on a simple topography made of a series of triangular prisms infinite in one direction (Figure S13). We use the best fit cohesion, $10 \mathrm{kPa}$, and friction, $35^{\circ}$ (Figure 3). First, we set $S=45^{\circ}$ (Figure 2e) and vary $L$. The modeled distribution is characterized by a rollover at small areas, a power law decrease, and a cutoff at large areas. Increasing $L$ and $H$ extends the maximum depth of the modeled landslides, and the tail of the modeled PDF has higher probability for larger landslide areas. Second, we set $L=960 \mathrm{~m}$ and vary $S$ (Figure 2f). An increase in $S$ and $H$ results in a shift of the rollover toward lower values and the tail of the modeled PDF shifts to higher probabilities for larger landslide areas. The range of modeled landslide areas reduces when reducing $S$. We also run the model varying concavity (Figure $2 \mathrm{~g}$ ). Convexity and concavity cause (1) the rollover to shift towards lower landslide depth or area values and (2) generate greater and smaller probabilities of large landslides, respectively. This shows the necessity of applying the model to real topographies to find accurate mechanical parameters.

Using $\gamma=0.47$, Figure 3 a shows $d_{\text {FIT }}$ as a function of cohesion and friction for Chi-Chi earthquake. We set arbitrarily $d_{\mathrm{FIT}} \leq 0.2$ as the range of acceptable models. Within this limit, the best fitting model parameters are those resulting in an absolute minima of $d_{\mathrm{FIT}}$. The best fit $C$ and $\Phi$ range between 15 and $21 \mathrm{kPa}$ and $22-34^{\circ}$, respectively. Figure $3 \mathrm{~b}$ shows a synthesis of the misfits for the six studied cases. The range of best fit $\gamma$ values, 0.47 to 0.56 , is narrow. The cohesion ranges are $3 \mathrm{kPa}$ (Niigata), $7-15 \mathrm{kPa}$ (Northridge), 8-18 $\mathrm{kPa}$ (Gorkha), 12-20 kPa (Wenchuan), 15-21 kPa (Chi-Chi), and 22-35 kPa (Morakot). The ranges for the frictional angles are broad: $10^{\circ}$ (Niigata), $17-35^{\circ}$ (Northridge), $35-52^{\circ}$ (Gorkha), $29-41^{\circ}$ (Wenchuan), 22-34 ${ }^{\circ}$ (Chi-Chi), and $10-25^{\circ}$ (Morakot).

\section{Discussion and Concluding Remarks}

Our model is capable, at first order, of isolating the relative contributions of mechanical processes and landscape geometry to landslide size distributions. It generates documented PDFs of landslide depth and area, including a rollover for small landslides, a power law decay for intermediate landslides, and a cutoff for large areas (Figure 2a). The rollover arises from the contribution of cohesion to hillslope stability, as suggested by Stark and Guzzetti (2009) and Frattini and Crosta (2013). Other potential explanations for this rollover include the undersampling of small landslides (Hovius et al., 1997; Hovius et al., 2000; Stark \& Hovius, 2001), landslide amalgamation (Tanyaş et al., 2018), and potential cohesion gradients with depth, in particular at the soil-rock transition (Frattini \& Crosta, 2013; Milledge et al., 2014). The power law behavior emerges from the correction for oversampling, based on the scaling relationship between landslide depth and area (Larsen et al., 2010). Because our model does not solve for lateral rupture propagation, this correction is required to account for the more likely sampling of a deep and large landslide than a shallow one. This supports the idea that rupture propagation leads to the emergence of a power scaling, as suggested by Stark and Guzzetti (2009). For larger landslides, the distribution deviates from this power law scaling by several orders of magnitude toward a distribution that reflects the variability of hillslope geometry. The cutoff at large landslide area results from the use of a topographic criterion combined to the finite size of hillslopes.

Our results illustrate the two major influences (Figures $2 \mathrm{e}-2 \mathrm{~g}$ ) of landscape shape on the PDFs of landslide depth or area. First, large landslide probability strongly depends on the available volume above the friction angle (Blöthe et al., 2015), and then on hillslope length, slope, and convexity. Second, because of the topographic criterion, steep slopes favor shallow and steep rupture planes. Indeed, cohesive strength at shallow depth dominates frictional strength (Figure S7), preventing the occurrence of gently dipping and more stable rupture planes. Our results are consistent with the idea that the PDF of landslide area is strongly influenced by the availability of high slope patches and that rheological mechanical properties modulate the power law exponent (Frattini \& Crosta, 2013). We extend this idea by showing that not only local slopes, but also the entire hillslope slope, height, length, and concavity control landslide size distribution, especially for large landslides.

The rupture plane geometry also influences the PDF of landslide area (Figure S4). For example, concave-up failure enhances large landslide probability compared to planar failure. However, the geometry of rupture is an open question in landslide modeling (Gallen et al., 2015) and observations show it dependency to many factors, such as the geometry of preexisting fractures (Lee et al., 2002; Sitar et al., 2005). Exploring several rupture geometries, Gallen et al. (2015) shown that concave-up failure planes allow reproducing the PDF of landslide areas. Here we show that such distribution can be recovered using a planar rupture geometry, but considering all the potential ranges of rupture angle and depth. To further understand how 2-D landslide 
propagation controls landslide size distribution, three-dimensional numerical modeling (e.g., Moon et al., 2017) would be a natural development of this work.

Comparing the modeled landslide distribution against natural data allows us to infer the best fitting mechanical and geometrical parameters. The range of best fit values of the depth-area scaling exponent $\gamma$ is narrow (0.47-0.56), compared to the initial reported range (0.2-0.7), and consistent with data (Larsen et al., 2010). Because friction poorly controls the PDF shape (Figure 2c), the best fit frictional angles are broad, 20-45 , except for Niigata, but in agreement with experimental measurements (Hoek \& Brown, 1997). The range of inferred cohesion, $10-35 \mathrm{kPa}$, is roughly comparable with those inferred from other models (Frattini \& Crosta, 2013; Gallen et al., 2015). These low cohesion values are more consistent with typical values of cohesion for soils with resisting roots, $10-30 \mathrm{kPa}$ (Sidle \& Ochiai, 2006), than for fractured or weathered bedrock, 0.1-1 MPa (Sutcliffe et al., 2004). Model parameters also show some interdependencies. Within the model parameter space, best fitting friction and cohesion are negatively and positively correlated with $\gamma$, respectively (Figure S8). For instance, changing the $\gamma$ value by $10 \%$ leads to a change of $10^{\circ}$ in the inferred friction angle (Figure S10). These trade-offs demonstrate the need for more studies dedicated to calibration of $\gamma$ in different regions.

The absence of a soil-rock transition, whose depth and angle could impose the geometry of some shallow landslides, is a limit of our model. However, the cohesion we infer is strongly dependent on shallow landslides, which stability is controlled by cohesion, while the inferred friction is more sensitive to deep landslides. In our model, the transition between cohesion- to friction-dominated strength occurs between 1 to $4 \mathrm{~m}$, close to the soil-rock transition (Figure S7). Moreover, because of the contribution of cohesion to shallow plane stability, unstable planes are steeper than their friction angle. Because of our geometric criterion, this results in nearly slope-parallel rupture planes close to the topographic surface, similarly to the geometry that is usually considered for shallow landslides. Therefore, our model captures some key features of soil landslides, even if it is not built according to soil mechanic principles.

Our simple mechanical model neglects static pore pressure and dynamic processes occurring during earthquakes and storms such as reduction of friction (Rice, 2012), pore pressure change, and passing seismic waves. In turn, we can interpret the inferred parameters from landslide inventories only in terms of effective friction and cohesion related to one triggering event. For instance, higher cohesion away from the fault trace (Figure S11) may reflect rock strength increase (Gallen et al., 2015) and ground shaking decrease (Valagussa et al., 2019). Therefore, using median values found in this study, $10<C<35 \mathrm{kPa}$ and 20 $<\Phi<45^{\circ}$, one could assess first-order prediction of landslide area distribution in a given landscape following an earthquake or storm event with more reliability than using higher, classical cohesion values. For instance, in the Dajia River basin in Taiwan, Typhoon Toraji triggered a distribution of landslides with a rollover at a larger area than for the distribution of landslides triggered by Chi-Chi earthquake (Huang \& Montgomery, 2014). According to our model, this change in rollover position could be interpreted as a change in cohesion. A possible explanation would be that pore pressure increase, following a typhoon, is mechanically equivalent to a reduction in frictional strength, whereas a reduction in effective cohesion could be more sensitive to the weakening induced by coseismic shaking (Marc et al., 2015). We would require more typhoon-induced triggered landslides to validate this hypothesis, which is in agreement with the low friction values inferred in this paper from the Morakot data set (Figure 3).

Interestingly, the PDFs of landslides triggered by Typhoon Toraji and the Chi-Chi earthquake also display different tails, with the probability of landslides $>10^{5} \mathrm{~m}^{2}$ much larger for the typhoon-triggered landslides (Huang \& Montgomery, 2014). According to our model, this could be interpreted as differences in hillslope geometry between the lowest part of the basin impacted by the earthquake and the higher and steeper part impacted by the typhoon. Moreover, the probability of large landslides triggered by Chi-Chi and Typhoon Morakot are of the same order of magnitude despite different triggering mechanisms (Figure S5). Both inventories encompass each other and cover a surface area of 10,000-20,000 $\mathrm{km}^{2}$, without marked differences in terms of topography at this scale. Both observations support the idea that landscape geometry exerts a first-order control on distribution of large landslides.

Our results have important geomorphological implications for landslides triggered in landscapes with different geomorphological properties. Our results imply that different landscapes should produce different landslide size distribution (Figures $2 \mathrm{e}$ and $2 \mathrm{f}$, and S12). The slope, height, and concavity of hillslopes are likely to exert a first-order control on the total landslide volume. This potentially explains the large 
Acknowledgments

Landslide data sets are available from https://www.sciencebase.gov website. We thank four anonymous reviewers for their helpful reviews of the manuscript. We also thank Alexander Densmore, Odin Marc, and Jean Braun for fruitful discussions and Kerry Gallagher and Jonathan Poh for having proofread the manuscript. variability of total landslide volume observed after earthquakes of similar magnitudes (Keefer, 1994; Marc et al., 2016), and the presence of extremely large paleolandslides $\left(>0.1 \mathrm{~km}^{3}\right)$ in regions characterized by high relief with long and steep slopes (Korup et al., 2007). Consequently, accounting for landscape shape is essential to improve hazard assessment, particularly in regions characterized by high relief and slope where large landslides may occur with high probability.

\section{References}

Alvioli, M., Guzzetti, F., \& Rossi, M. (2014). Scaling properties of rainfall induced landslides predicted by a physically based model. Geomorphology, 213, 38-47.

Blöthe, J. H., Korup, O., \& Schwanghart, W. (2015). Large landslides lie low: Excess topography in the Himalaya-Karakoram ranges. Geology, 43(6), 523-526.

Burbank, D. (2002). Rates of erosion and their implications for exhumation. Mineralogical Magazine, 66(1), 25-52.

Chang, K. T., Chiang, S. H., Chen, Y. C., \& Mondini, A. C. (2014). Modeling the spatial occurrence of shallow landslides triggered by typhoons. Geomorphology, 208, 137-148.

Densmore, A. L., Ellis, M. A., \& Anderson, R. S. (1998). Landsliding and the evolution of normal-fault-bounded mountains. Journal of Geophysical Research, 103(B7), 15,203-15,219.

Duncan, C. W., \& Christopher, W. M. (2004). Rock slope engineering: Civil and mining. New York: Spon Press.

Dussauge, C., Grasso, J. R., \& Helmstetter, A. (2003). Statistical analysis of rockfall volume distributions: Implications for rockfall dynamics. Journal of Geophysical Research, 108(B6), 2286. https://doi.org/10.1029/2001JB000650

Frattini, P., \& Crosta, G. B. (2013). The role of material properties and landscape morphology on landslide size distributions. Earth and Planetary Science Letters, 361, 310-319.

GSI (2005). 1:25,000 Damage map of the mid Niigata Prefecture earthquake in 2004: 3sheets, edited, (Tech Rep.)

Gallen, S. F., Clark, M. K., \& Godt, J. W. (2015). Coseismic landslides reveal near-surface rock strength in a high-relief, tectonically active setting. Geology, 43(1), 11-14.

Guzzetti, F., Malamud, B. D., Turcotte, D. L., \& Reichenbach, P. (2002). Power-law correlations of landslide areas in central Italy. Earth and Planetary Science Letters, 195(3-4), 169-183.

Harp, E. L., \& Jibson, R. W. (1995). Inventory of landslides triggered by the 1994 Northridge, California earthquake.

Hoek, E., \& Brown, E. T. (1997). Practical estimates of rock mass strength. International Journal of Rock Mechanics and Mining Sciences, 34(8), 1165-1186.

Hovius, N., Meunier, P., Lin, C. W., Chen, H., Chen, Y. G., Dadson, S., \& Lines, M. (2011). Prolonged seismically induced erosion and the mass balance of a large earthquake. Earth and Planetary Science Letters, 304(3), 347-355.

Hovius, N., Stark, C. P., \& Allen, P. A. (1997). Sediment flux from a mountain belt derived by landslide mapping. Geology, 25(3), 231-234.

Hovius, N., Stark, C. P., Hao-Tsu, C. Harp, \& Jiun-Chuan, L. (2000). Supply and removal of sediment in a landslide-dominated mountain belt: Central Range, Taiwan. The Journal of Geology, 108(1), 73-89.

Huang, A. Y. L., \& Montgomery, D. R. (2014). Topographic locations and size of earthquake-and typhoon-generated landslides, Tachia River, Taiwan. Earth Surface Processes and Landforms, 39(3), 414-418.

Katz, O., \& Aharonov, E. (2006). Landslides in vibrating sand box: What controls types of slope failure and frequency magnitude relations? Earth and Planetary Science Letters, 247(3), 280-294.

Keefer, D. K. (1994). The importance of earthquake-induced landslides to long-term slope erosion and slope-failure hazards in seismically active regions. Geomorphology, 10(1), 265-284.

Korup, O. (2005). Distribution of landslides in southwest New Zealand. Landslides, 2(1), 43-51.

Korup, O., Clague, J. J., Hermanns, R. L., Hewitt, K., Strom, A. L., \& Weidinger, J. T. (2007). Giant landslides, topography, and erosion. Earth and Planetary Science Letters, 261(3), 578-589.

Larsen, I. J., Montgomery, D. R., \& Korup, O. (2010). Landslide erosion controlled by hillslope material. Nature Geoscience, 3(4), $247-251$.

Lee, S., Chwae, U., \& Min, K. (2002). Landslide susceptibility mapping by correlation between topography and geological structure: the Janghung area, Korea. Geomorphology, 46(3-4), 149-162.

Li, G., West, A. J., Densmore, A. L., Jin, Z., Parker, R. N., \& Hilton, R. G. (2014). Seismic mountain building: Landslides associated with the 2008 Wenchuan earthquake in the context of a generalized model for earthquake volume balance. Geochemistry, Geophysics, Geosystems, 15, 833-844. https://doi.org/10.1002/2013GC005067

Liao, H. W., \& Lee, C. T. (2000). Landslides triggered by the Chi-Chi earthquake. In Proceedings of the 21st asian conference on remote sensing, taipei, 1 (pp. 2). Taipei

Liucci, L., Melelli, L., Suteanu, C., \& Ponziani, F. (2017). The role of topography in the scaling distribution of landslide areas: A cellular automata modeling approach. Geomorphology, 290, 236-249.

Malamud, B. D., \& Turcotte, D. L. (1999). Self-organized criticality applied to natural hazards. Natural Hazards, 20(2), 93-116.

Malamud, B. D., Turcotte, D. L., Guzzetti, F., \& Reichenbach, P. (2004a). Landslide inventories and their statistical properties. Earth Surface Processes and Landforms, 29(6), 687-711.

Malamud, B. D., Turcotte, D. L., Guzzetti, F., \& Reichenbach, P. (2004b). Landslides, earthquakes, and erosion. Earth and Planetary Science Letters, 229(1), 45-59.

Marc, O., Hovius, N., \& Meunier, P. (2016). The mass balance of earthquakes and earthquake sequences. Geophysical Research Letters, 43, 3708-3716. https://doi.org/10.1002/2016GL068333

Marc, O., Hovius, N., Meunier, P., Uchida, T., \& Hayashi, S. (2015). Transient changes of landslide rates after earthquakes. Geology, 43(10), 883-886.

Marc, O., Stumpf, A., Malet, J. P., Gosset, M., Uchida, T., \& Chiang, S. H. (2018). Towards a global database of rainfall-induced landslide inventories: first insights from past and new events.

Massey, C., Townsend, D., Rathje, E., Allstadt, K. E., Lukovic, B., \& Kaneko, Y. (2018). Landslides Triggered by the 14 November 2016 M w 7.8 Kaikoura Earthquake, New Zealand. Bulletin of the Seismological Society of America, 108(3B), 1630-1648.

Meunier, P., Hovius, N., \& Haines, A. J. (2007). Regional patterns of earthquake-triggered landslides and their relation to ground motion. Geophysical Research Letters, 34, L20408. https://doi.org/10.1029/2007GL031337 
Milledge, D. G., Bellugi, D., McKean, J. A., Densmore, A. L., \& Dietrich, W. E. (2014). A multidimensional stability model for predicting shallow landslide size and shape across landscapes. Journal of Geophysical Research: Earth Surface, 119, 2481-2504. https://doi.org/10. 1002/2014JF003135

Moon, S., Perron, J., Martel, S., Holbrook, W., \& St. Clair, J. (2017). A model of three-dimensional topographic stresses with implications for bedrock fractures, surface processes, and landscape evolution. Journal of Geophysical Research: Earth Surface, 122, 823-846. https:// doi.org/10.1002/2016JF004155

Parker, R. N., Densmore, A. L., Rosser, N. J., De Michele, M., Li, Y., Huang, R., \& Petley, D. N. (2011). Mass wasting triggered by the 2008 Wenchuan earthquake is greater than orogenic growth. Nature Geoscience, 4(7), 449-452.

Pelletier, J. D., Malamud, B. D., Blodgett, T., \& Turcotte, D. L (1997). Scale-invariance of soil moisture variability and its implications for the frequency-size distribution of landslides. Engineering Geology, 48(3), 255-268.

Roback, K., Clark, M. K., West, A. J., Zekkos, D., Li, G., Gallen, S. F., \& Godt, J. W. (2017). The size, distribution, and mobility of landslides caused by the $2015 \mathrm{M}$ w 7.8 Gorkha earthquake, Nepal. Geomorphology, 301, 121-138.

Schwanghart, W., \& Scherler, D. (2014). TopoToolbox 2-MATLAB-based software for topographic analysis and modeling in Earth surface sciences. Earth Surface Dynamics, 2(1), 1-7.

Sidle, R. C., \& Ochiai, H. (2006). Landslides: Processes, prediction, and land use. Washington: American Geophysical Union.

Sitar, N., MacLaughlin, M. M., \& Doolin, D. M. (2005). Influence of kinematics on landslide mobility and failure mode. Journal of Geotechnical and Geoenvironmental Engineering, 131, 716-728. https://doi.org/10.1061/(ASCE)1090-0241(2005)131:6(716)

Stark, C., \& Guzzetti, F. (2009). Landslide rupture and the probability distribution of mobilized debris volumes. Journal of Geophysical Research, 114, F00A02. https://doi.org/10.1029/2008JF001008

Stark, C. P., \& Hovius, N. (2001). The characterization of landslide size distributions. Geophysical Research Letters, $28(6), 1091-1094$.

Sutcliffe, D., Yu, H., \& Sloan, S. (2004). Lower bound solutions for bearing capacity of jointed rock. Computers and Geotechnics, 31(1), 23-36.

Tanyaş, H., van Westen, C. J., Allstadt, K. E, \& Jibson, R. W. (2018). Factors controlling landslide frequency-area distributions. Earth Surface Processes and Landforms.

Valagussa, A., Marc, O., Frattini, P., \& Crosta, G. (2019). Seismic and geological controls on earthquake-induced landslide size. Earth and Planetary Science Letters, 506, 268-281.

Van Den Eeckhaut, M., Poesen, J., Govers, G., Verstraeten, G., \& Demoulin, A. (2007). Characteristics of the size distribution of recent and historical landslides in a populated hilly region. Earth and Planetary Science Letters, 256(3), 588-603.

Rice, J. R. (2012). Nucleation Of slip-weakening rupture instability in landslides by localized increase of pore pressure. Journal of Geophysical Research, 17, B03104. https://doi.org/10.1029/2011JB008866

Xu, C., Xu, X., Yao, X., \& Dai, F. (2014). Three (nearly) complete inventories of landslides triggered by the May 12, 2008 Wenchuan Mw 7.9 earthquake of China and their spatial distribution statistical analysis. Landslides, 11(3), 441-461. 